\section{Más allá del otro sendero}

\author{
Jaime Bailón
}

El presente artículo reafirma el exE pectante lugar del sector informal en la economía peruana, su injerencia en el campo de la producción simbólica (discos y promotoras de espectáculos) confirma este liderazgo. La venta de discos piratas ha puesto en jaque a las empresas transnacionales, otro tanto sucede con el hardware y software del campo informático. En los puestos de los mercados y plazas del centro de Lima nuestros monstruos en computación resuelven problemas técnicos y de abastecimiento en minutos. La epopeya de estas empresas y los afanes de los pro hombres del márketing cholo, son los protagonistas del siguiente informe. Los gurúes del márketing y la economía contemporánea no se cansan de repetir al unísono que una de las principales prácticas de las organizaciones vanguardistas es la innovación. Esto no significa necesariamente destinar esfuerzos en la creación de productos o dispositivos novedosos. Es más bien adaptarse constantemente a las cambiantes necesidades de los consumidores. En este sentido, la apuesta por nuevas formas de producción y comercialización de productos, así como la consolidación y conquista de nuevos mercados son los objetivos centrales de la nueva casta empresarial. Innovación o muerte es el grito de batalla de los revolucionarios del siglo XXI. Aunque esta frase encierra un terrible dilema. Muchas veces la búsqueda de la innovación demanda 
enormes costos económicos para su implantación, produciendo la desaparición de las empresas antes de siquiera haber puesto en marcha sus nuevos productos y estrategias. Pero la muerte es una de las reglas del mercado, como también las resurrecciones con nuevos nombres y razón social.

Uno de los sectores que mejor han internalizado las nuevas reglas del juego económico es el sector informal. Cuando Hernando de Soto publicó El otro sendero en 1986, no solo hizo visible la informalidad; también puso el énfasis en su importancia social y económica. Este sector ha sido el principal constructor y empleador del país. Con anterioridad a De Soto el sector informal era visto, en el mejor de los casos, como una estrategia de supervivencia $\mathrm{y}$, en el peor, como una actividad lindante con la delincuencia.

Actualmente estas dos perspectivas todavía se mantienen, pero la posmodernización económica podría otorgarle al sector informal un abanico de insospechadas posibilidades de crecimiento.

\section{La sociedad del conocimiento. La universidad... iya fue!}

El término posmodernización es una de las formas de denominar el nuevo paradigma de la economía (otros lo denominan poscapitalista o sociedades de control). Empresas del sector servi- cios, especialmente las relacionadas con el campo de las comunicaciones y la informática, son las que registran mayor rentabilidad. Pero la agricultura y las industrias de bienes durables no han desaparecido. Sus métodos de trabajo están siendo adoptados paulatinamente a la lógica de la producción simbólica contemporánea. Es decir que la estructura organizacional caracterizada por una disciplina vertical y homogénea, propia de la producción fabril del siglo pasado, viene siendo reemplazada por un esquema que privilegia una administración descentralizada con altos niveles de autonomía para sus agentes, y una producción que tiene como base el mercado. Las organizaciones posmodernas no pueden desviarse de su finalidad principal: la administración y satisfacción de la demanda. El personal, por lo tanto, no debe distraer sus funciones de los objetivos centrales de la organización: En un hospital médicos y enfermeras deben atender pacientes y no trámites burocráticos. En la universidad los profesores deben enseñar e investigar y dejar la administración a especialistas.

El outsourcing es una de las principales herramientas de la organización poscapitalista y más que tercerizar (contratar compañías de vigilancia) trata de establecer y compartir vínculos con otras organizaciones que puedan realizar mejor las tareas que no son el núcleo central de nuestro negocio o servicio. 
La puesta en marcha de esta nueva concepción de la administración exige trabajadores con altos niveles de calificación y especialización. La universidad peruana no está capacitada para formarlos: su organización en facultades (división del conocimiento en cotos cerrados), costos excesivos y largos periodos de formación inútil, ahuyentan y frustran al público juvenil. Si bien los sectores de la Lima tradicional todavía ven en ella una vía de ascenso social, los jóvenes de la Lima norte, sur y este (los antiguos conos) encuentran en los institutos tecnológicos el vehículo adecuado para su formación. La principal virtud de estas instituciones es que terminan con la absurda división entre formación educativa y actividad laboral. La idea es que el estudiante pueda desempeñarse simultáneamente en los campos educativo y profesional, estableciendo un ejercicio de constante retroalimentación entre ambos campos.

Estos institutos, más que enseñar contenidos sofisticados tratan de desarrollar las capacidades de sus estudiantes, brindando las herramientas para que estos puedan seguir aprendiendo por su cuenta.

Sociedad del conocimiento es la otra denominación del paradigma posmoderno, refiriéndose a un saber con altos niveles de especialización e interconexión. Las nuevas organizaciones necesitan profesionales capa- citados para trabajar en equipos, formados en la praxis de la educación continua y familiarizados con el software básico de su campo de acción profesional.

\section{Las invasiones bárbaras}

La empresa contemporánea es producto del márketing. Los flujos de comunicación con el entorno constituyen su razón de ser. No existen fronteras, las nuevas tecnologías se encargan de diluirlas constantemente. Todas las organizaciones son producto de infinidad de agenciamientos y alianzas estratégicas. La concepción de la empresa como una organización autónoma ha llegado a su fin.

El sector informal, por su propio tamaño, estatus legal y volumen de capital, es el primero en implementar estos agenciamientos. Los talleres de calzado sin licencia de funcionamiento tienen que diversificar sus territorios de producción. Otro tanto sucede con las empresas que fabrican discos piratas, tampoco pueden centralizarse en un solo lugar.

Además, utilizan de manera eficiente las tácticas del márketing mix, que consiste en la mezcla de las decisiones del producto, precio, provisión y promoción. En el caso de la piratería, no existe una diferencia sustantiva entre el producto original y la copia pirata (salvo el diseño de las 
carátulas, detalle que viene siendo mejorado constantemente). El precio es el plato fuerte de los informales, a diferencia de un original su precio puede ser veinte veces más bajo (existen grabaciones de un dólar). La distribución está garantizada por su ejército de vendedores esparcidos por toda la ciudad.

Los músicos de tecnocumbia y tecnohuayno, lejos de amedrentarse ante la piratería, han establecido con los vendedores de este material una alianza estratégica. Las grabaciones corren a cargo de los promotores de los grupos y la distribución del material es encargada a los vendedores piratas. Si bien con este sistema no se obtienen ganancias importantes, la producción del disco, gracias a las nuevas tecnologías, tampoco ha sido onerosa. La discografía es básicamente un elemento de promoción del grupo o cantante. El rendimiento económico se obtiene de los conciertos y la venta de cerveza (algunas agrupaciones expenden sus propias marcas). Estas bandas le han cambiado el sentido a la industria musical, reformulando el negocio. En este caso la piratería no ha matado la música, por el contrario, el vendaval andino de polleras multicolores está realizando una de sus invasiones más exitosas: el territorio mediático.

Las multitudes y sus creativos se apropian, bailan, recrean y fundan de nuevo la ciudad... su ciudad. 